\title{
LXXIII. On the magnetism of steam
}

\section{Reuben Phillips Esq.}

To cite this article: Reuben Phillips Esq. (1849) LXXIII. On the magnetism of steam, Philosophical Magazine Series 3, 34:232, 502-511, DOI: $10.1080 / 14786444908646283$

To link to this article: http://dx.doi.org/10.1080/14786444908646283

$$
\text { 册 Published online: } 30 \text { Apr } 2009 .
$$

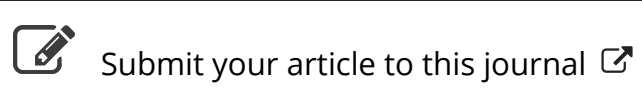

\footnotetext{
Џll Article views: 2
}

Q View related articles $\sqsubset$ 
dition is fulfilled, and I continue to deny it. Hence Professor Challis is mistaken in supposing that I admitted what before I denied, and denied what before I admitted.

It is not my intention to attack Professor Challis's new views respecting the theoretical velocity of sound; because if Professor Challis and I cannot agree on what to my own mind seems so plain a matter as the theory of spherical waves, I see little chance of our agreeing on the subject I have mentioned.

$$
\begin{aligned}
& \text { I am, Gentlemen, } \\
& \begin{array}{c}
\text { Your obedient Servant, } \\
\begin{array}{c}
\text { Pembroke College, Cambridge, } \\
\text { June 5, 1849. }
\end{array}
\end{array}
\end{aligned}
$$

\section{On the Magnetism of Steam. By Reuben Phillips, Esq.*}

1. THE following investigation has resulted from an at1 tempt made with a view to the better understanding of the relation between electric and magnetic forces, by ascertaining whether the only form of the electric current, the nature of which, principally from the researches of Dr. Faraday, is very completely comprehended, possesses the usual magnetic properties. In this I was baffled (but the way is now open) by an unexpected phænomenon, the nature of which it became of primary consequence to develope, and which forms the subject of the present paper.

2. A little wooden stick was laid across the mouth of a small Bohemian beaker; the stick was placed parallel with the bottom of the glass, and held in its position with sealingwax: the beaker was 3.5 inches high. A common sewingneedle No. 7, and another No. 8, were magnetized and stuck through a slip of thin card, the north end of one magnet being opposed to the south of the other, the needles being two inches apart. This partially astatic arrangement was suspended from the stick by a single fibre of silk, and the length of the fibre between the points of suspension was one inch. The needles made one vibration in about two seconds. I found if the needles were much more astatic than this, they were very subject to slow irregular variations of position, which appeared to proceed from a twisting of the silk arising from changes in its hygrometric or calorific condition. The mouth of the glass was closed with a card cover furnished with a rim.

3. The beaker was now placed on the stage of a microscope

- Communicated by the Author. 
and fastened to the triangular bar by means of cork and thread, and a hole about an inch across was cut in the card cover, the centre of the hole being over the point of the uppermost needle; the arm for carrying the optical tube was now brought over the hole, and then the optical tube, fitted with an objectglass, was screwed into its place; the arm came down nearly close upon the card cover, and the tube of the object-glass passed through the cover and stood over the point of the upper needle. The fine adjustment was used to focus the instrument; and to bring the point of the needle to its right position under the object-glass, I employed the motion of the arm which carried the optical tube, and also that imparted to the whole instrument by laying hold on the extremity of one of the prongs of the tripod stand and making it describe a small portion of a circle on the table. The point of the needle was viewed by means of a pencil of light thrown from the mirror through the battom of the beaker. The magnifying power used was about $\mathbf{4 5 0}$ diameters.

4. A micrometer eye-piece was employed, the scale of which formed an angle of about $25^{\circ}$ with the edge of the needle to be observed. The optical power of this micrometer corresponded to the third, or deepest eye-piece, with which microscopes are generally furnished ; because that for such experiments a shallow object-glass is to be preferred.

5. This galvanoscope was sheltered by a rectangular zinc plate, $\cdot 1$ inch thick, bent somewhat into the shape of the smaller segment of the convex surface of a right cylinder, made by a plane parallel to, and at a considerable distance from, its axis. The length of a line drawn perpendicularly from one straight side to the other was 10 inches, and the maximum length of a perpendicular drawn to this line and extending to the nearest point of the zinc was 2.8 inches; in consequence of this curve, the zinc plate could easily be made to stand on end, in which position it was 18.5 inches high. This shield was employed throughout all the following experiments on steam.

6. In order to obtain accurate results, I found it necessary to avoid moving any mass of iron near the galvanoscope, and also to keep moderately still, although the hands and arms could be freely used without affecting the galvanoscope. During these experiments I sometimes observed a very singular effect produced on the magnetic needles: when the steam was turned on, the needle would begin to move across the field of view with a peculiar slow motion; and when the steam was shut off, it as slowly or more slowly returned to its former position, one of such vibrations occupying half a minute or more. This I at length found was produced by the steam 
heating the zinc shield; and thus this motion could be produced or avoided at pleasure, and was, I think, sufficiently accounted for.

7. The steam was obtained from a small hydro-electric machine; and the various apparatus for effecting the discharge were screwed into the condenser at the place made to receive the Armstrong's jet. The condenser was always dry, except where I have noted the contrary, and the steam was discharged horizontally towards the north.

8. A galvanic current was sent through a wire in the neighbourhood of the galvanuscope; the wire lay parallel with the needles in the path taken by the steam (9.), and acted about equally on both; the wire of course lay about north and south, and the electricity passed along it from north to south, supposing the current to pass through the conducting wire of a voltaic circle from the platinum to the zinc. When the circuit was completed, the needle moved to one side, A, of the field of view from the opposite side C. Throughout these experiments the motion of the same end of the same needle was always recorded, and the galvanoscope always stood to the east of the current of steam.

9. To a brass jet, $1 \cdot 8$ inch long, was fastened a piece of glass tube, 11.5 inches long and $\frac{3}{20}$ inch diameter inside, and the juncture was made tight, or nearly so, with caoutchouc; the aperture at the end of the brass jet which projected from the condenser (7.) was circular, and $\frac{1}{12}$ inch in diameter. The nearest point of the convex surface of the zinc shield was about $\frac{1}{10}$ inch from the glass tube; the stage of the microscope in this and the following experiments came nearly close to the shield. The fibre which suspended the needles was about $1 \frac{3}{4}$ inch from the nearest part of a plane drawn through the end of the brass jet, and making a right angle with its bore; the steam was used in this experiment at about $35 \mathrm{lbs}$. on the inch. Things being so arranged, I found when the steam was turned on that the needle immediately began to move towards $\mathrm{C}$; and by alternately checking the steam and letting it off, a considerable swing of the needles was produced; and by reversing the times of letting off the steam, the swing of the needles could be again reduced. I had ascertained by previous trials, that turning the cock of the boiler without letting off the steam produced no effect on the needles. The experiment was made by screwing a stop-cock in the place of the above-mentioned brass jet; and then the cock of the boiler could be worked without letting off the steam, and without affecting the galvanoscope.

10. The galvanoscope was raised a few inches, so that the 
steam might act principally on the lower side of the undermost needle, instead of acting equally on both as before, everything else being as in the former experiment. When the steam was turned on, the needle began to move towards $A$; and by alternately shutting off the steam and letting it issue at the corresponding positions of the needle, a vibration through full half of the micrometer was obtained; and then by making the blasts of steam synchronical with the opposite vibrations of the needle, the motion was checked.

11. The glass tube was now taken away, the galvanoscope lowered as in (9.), and the shield and galvanoscope moved horizontally about $\frac{3}{4}$ inch in a perpendicular direction to the path of the steam, which was used at about 35 pounds on the inch. Operating as before, I could with this jet of steam more easily obtain the swing, the motion being towards $\mathrm{C}$ when the steam was turned on. Water being placed in the Armstrong's condenser, produced no alteration in the magnetic effects of the jet of steam.

12. The effect of this jet (11.) was much greater than that of the current of electricity of an Armstrong's jet under the most favourable circumstances. The comparison was made in the following manner:-I found that an Armstrong's jet could discharge more steam in a given time than the brass jet (11.), also that the electricity produced by the Armstrong's jet could deflect the needle of a galvanometer of the ordinary construction 3 or 4 degrees. I then found that a small voltaic arrangement capable of deflecting the needles of the galvanometer $4^{\circ}$, and having a conducting wire lying in the path of the steam, acted far less on the needles of the galvanoscope than the blast of steam from the brass jet (11.). Also when an Armstrong's jet was substituted for the brass jet, and water placed in the condenser, $\bar{I}$ could perceive no difference in the swing, whether the steam passed by the galvanoscope in a highly electrified condition, or whether the electricity was, in a great measure, collected by means of a number of fine points almost as soon as it left the wooden channel. The points were supplied by two small concentric loops of wire-gauze, placed edgeways in the steam at a distance in different experiments of from $\frac{1}{2}$ to $\frac{3}{1}$ inch from the end of the Armstrong's jet. The galvanoscope was as before (11.), except that it was placed about $\frac{3}{4}$ inch further from the jet, but at about the same distance from the path of the steam.

13. There is a singular variation which I have sometimes observed in the magnetic effect produced by the steam issuing from an Armstrong's jet; namely, that the action of the steam on the galvanoscope is much stronger when one of the needles 
is in the same horizontal plane as the central line of the path of the steam, than when the galvanoscope is placed so that the steam may pass equally near to both needles. I have occasionally observed the swing to be five or six times greater in one position than in the other; but sometimes the swing is the same in either position. I have not perceived a similar effect with any other jet.

14. A pewter tube 6 feet long, having a bore $\frac{3}{2} 0$ inch diameter, was coiled up after the fashion of the wire of a galvanometer: it made six convolutions. One end of the tube was jambed on the brass jet (9.), and the coil stood horizontally like the coil of a galvanometer; the zinc shield was brought nearly close to the coil, and the height of the galvanoscope was adjusted so that the coil might act on both the upper and lower sides of the lower needle; the steam entered on the upper side of the coil in the same direction as before. $B y$ this arrangement $I$ succeeded in producing a marked swing with steam of a very low pressure, I think below $5 \mathrm{lbs}$. on the inch; but I did not exactly ascertain the amount of this low pressure, because the safety-valve of the boiler is not graduated below $40 \mathrm{lbs}$. As the pressure rose, the power exerted on the needles became greater; and at $40 \mathrm{lbs}$. on the inch, a few puffs of steam caused the needle to move through the whole length of the micrometer; the motion, when the steam was turned on, being towards $\mathbf{C}$.

15. Instead of allowing the steam to pass continuously through the tube during the whole of each alternate vibration, it was shut off before the vibration was completed. The swing was now much less, showing that it was not the first gust of steam which alone moved the needles; and this agreed with the visible motion of the needle, which manifestly increased in velocity after it began to move.

16. Water being placed in the condenser of the hydroelectric machine did not sensibly alter the force exerted on the needles by the coil.

17. The coil was now attached to the boiler by means of a piece of brass, the steam-way of which was so large that the coil only might be looked upon as opposing the exit of the steam. Various pressures were tried, as the boiler became heated, up to 40 lbs. per inch. A lead pipe was, in this experiment and frequently afterwards, placed at a short distance from the coil to catch the steam and convey it up a chimney, whereas in former experiments it had freely escaped into the apartment; everything else remained as before (14.). The needles began to be affected at a very low pressure; and as the pressure increased, the swing became certain and steady, the needle 
moving towards $\mathrm{C}$ when the steam was turned on. The intensity of the swing-producing force was, I think, at its maximum at 10-15 lbs. per inch; as the pressure rose, the swing was obtained with more difficulty, and at $40 \mathrm{lbs}$. on the inch no certain swing could be produced. On repeating this experiment at a subsequent period with steam at $40 \mathrm{lbs}$, on the inch, a feeble swing was obtained; but in this latter case the coil, instead of being bright, had become covered with a deposit of carbonate of lime.

18. The galvanoscope was lowered until the upper needle was in the same horizontal plane as the undermost side of the upper portion of the coil, and the lower needle was in a horizontal plane which came to about $\frac{1}{4}$ inch below the lower surface of the lower half of the coil. When the steam was turned on, the needle made a start towards $A$; and by shutting off the steam during the next vibration, and repeating these operations two or three times, a considerable swing was obtained; but on attempting to increase this swing by continuing these intermittent operations, the swing rapidly diminished. The order in which the jet of steam and its cessation took place was now inverted, which soon produced a very powerful swing, the needle moving towards $\mathrm{C}$ when the steam was turned on. The steam was used at from 30 to $40 \mathrm{lbs}$. on the inch. These rather irregular motions $(17,18$.) are probably connected with those of the Armstrong's jet (13.).

19. The coil was moved through an angle of $180^{\circ}$, the angular motion being performed parallel to a plane forming a right angle to the path of the steam, and the galvanoscope was adjusted so that the interior surface of the coil might act on the lower needle; by this arrangement the direction of the steam as regards the needle was reversed. Many different pressures were observed from a pound or two on the inch to 40 lbs. As soon as any distinct swing was produced, it was occasioned by the needle moving towards $A$ when the steam was turned on; as the pressure rose, this swing increased until the steam was, I think, about $25 \mathrm{lbs}$. on the inch, after which the increased pressure only occasioned a somewhat diminished swing.

20. The apparatus (19.) was now rather differently disposed, the shield and galvanoscope were moved horizontally about $\frac{3}{4}$ inch, the direction of the motion beir $g$ perpendicular to the path of the steam; also a piece of an i ron gun-barrel 7 inches long and open at both ends, was fixed to a support, so that the gun-barrel might easily be thrust into, or removed from, the coil without bearing upon it; the axis of the gun-barrel when placed in the coil formed a right angle to the path of the steam, and was horizontal, and its direction lay not far 
from east and west; also one end came to $\frac{1}{5}$ inch of the shield opposite to the lower needle of the galvanoscope. This piece of a gun-barrel had been made red-hot and slowly cooled, and its magnetism when in the above position was nearly $=0$; the diameter of its external surface at that end which was placed in the coil, in this and the following experiments, was about one inch, and this end was made of iron about $\frac{1}{10}$ inch thick, the other end being thinner. There was a distance of about $\frac{1}{3}$ inch between the nearest upper or lower part of the iron and the respective inside surfaces of the coil.

21 . The steam being at $40 \mathrm{lbs}$. per inch, and the gun-barrel in the coil, five puffs of steam, each puff acting during every alternate vibration of the needles, produced a swing of about $25^{\circ}$ of the micrometer; the gun-barrel was now removed, when five puffs of steam, acting as before, produced a vibration of only $10^{\circ}$. This was done many times, and always with the same result. I think better results would have been obtained at a lower pressure than $40 \mathrm{lbs}$.; for on examining the vibration at various pressures, the iron being in the coil, I found that a considerable swing was produced almost as soon as the water began to boil at the atmospheric pressure; and shortly afterwards, as the pressure rose, the vibrations became very strong, much stronger than at 40 lbs. 'The point of the needle moved towards $A$ when the steam was turned on.

22. During these last experiments, I ascertained that the first puff of steam which passed through the coil when it was cold produced a much greater effect on the galvanoscope than any immediately succeeding puff. This was guarded against by letting off the first puff, then checking the motion of the needles by some inverse puffs, and then proceeding to make the vibration which was to be compared (21.).

23. I next endeavoured to find the cause of the strong action of the first puff.

24. The jet and pewter coil (14.), instead of being affixed to the boiler, were attached to a copper box, which inclosed about ninety cubic inches, and the shield and galvanoscope adjusted as before (14.); air was now pumped into the box until the pressure rose to about 40 lbs. on the inch, and then discharged through the jet as the steam had been. The needles of the galvanoscope were quite unaffected; consequently, air of about the same temperature as the surrounding atmosphere cannot act on a magnet like steam.

25. It now appeared very possible that the increased action produced by the iron arose from its cooling powers; and also that by further cooling the coil, a more intense action would be obtained.

26. The apparatus (17.) had the coil partly immersed in 
water, by bringing a copper pan filled with water under it, so that the water might cover the lower portion of the coil; the upper portion of the coil was kept moist by having had some loosely spun cotton twisted about it, the ends of which dipped into the water. The gun-barrel was placed in the coil much as before (20.), and was supported without touching the coil ; consequently any little alteration, produced by the heat of the steam, in the position of the coil, could not move the iron; the gun-barrel lay entirely under water. The steam was used at 35 to 4.0 lbs. on the inch, as at that pressure a difference of a few pounds did not much affect the galvanoscope. A few puffs of steam made the water about the coil to boil; after which, when the circumstances of the experiment appeared to be very steady, I observed that one puff of steam could move the edge of the needle across the field of view. The gun-barrel was removed, and now two or three puffs of steam, acting through each alternate vibration, could only produce a swing half across the micrometer. A solid brass rod, $\cdot 7$ inch diameter and about 6 inches long, being now laid in the place of the gun-barrel, produced no alteration in the swing of the magnetic needles; the brass rod being removed, and the gunbarrel replaced, the motion of the magnets at once became as strong as before. It now follows that the action of the iron on the galvanoscope is independent of any little change of temperature it may produce. The swing was towards $\mathbf{C}$ when the steam was turned on.

27. In these experiments I did not perceive any difference between the first and following puffs of steam; and the swing was, I think, at least as great at 40 lbs. as at any lower pressure.

28. The brass jet (9.) was screwed into the end of the coil from which the steam escaped (26.), which apparatus in other respects remained as before; this alteration caused an increased pressure in the coil, and the condensation was consequently very rapid; so much so, that what escaped from the brass jet looked more like water than steam. The swing, when the gun-barrel was either in or out of the coil, remained just as before (26.), the pressure in the boiler being about $40 \mathrm{lbs}$. on the inch.

29. A pewter tube, 9 feet long and $\frac{1}{4}$ inch internal diameter, was made into a dense cylindrical coil 4 inches long, the diameter of the external surface of which was 2.5 inches, and the diameter of the interior 1.25 inch. This coil was attached to the boiler by means of a short brass connecting piece, the steam-way of which was cylindrical, and $\frac{3}{20}$ inch diameter; the coil was supported horizontally, and pointed about east 
and west. The shield stood $\frac{1}{5}$ inch at its nearest part from the end of the coil, and the galvanoscope was adjusted so that the lower needle was opposite to the coil ; the steam circulated in the same direction as before $(14,26$.$) . At 40$ lbs. four puffs of steam produced a swing about one-fourth across the micrometer, and the swing was not very much stronger at any lower pressure. The copper pan, which had previously been placed in position under the coil, was now filled with water, by which the coil was about half-covered. The first motions of the needle were not very powerful; but after three or four puffs, which heated the water about the coil, one puff of steam would move the needle from $\mathrm{A}$ quite out at $\mathrm{C}$; the swing was in the same direction when there was no water in the pan.

30. 'The cylindrical pewter coil had a turn or two opened out, in order to give sufficient length between the brass connecting piece and the coil to allow the latter to be immersed in the water of the copper pan. The gun-barrel was placed in the coil, and was supported by wires attached to the copper pan, and so prevented from touching the coil ; the gun-barrel projected about $\frac{1}{2}$ inch beyond the end of the coil on the side nearest to the galvanoscope. The optical tube of the galvanoscope was removed, and the hole in the cover was closed with a piece of glass. 'The steam was used at about $40 \mathrm{lbs}$. on the inch. After the water in the copper pan had been heated, I could easily by successive puffs of steam produce a vibration through an arc of 20 or 30 degrees.

31. Putting together these gun-barrel experiments, and that with condensed air (24.), I come to the conclusion that a difference of temperature is necessary to produce these peculiar magnetic effects; which accounts for the greater force of the first blast of steam (22.), and for the superior force of a jet (11.). Also the similarity which exists between the magnetic effects of the steam current, and the magnetic effects of the voltaic current, both as regards magnets and soft iron, renders it nearly or quite certain that this force of the steam is magnetism.

32. Now a jet of steam, even when mixed with much water, is an excellent non-conductor of electricity; for when discharged from an Armstrong's jet, it is seen that electricity even of a very high intensity cannot pass throngh it, and a jet of dry stean must be at least as good a non-conductor; hence the jet of steam (11.) cannot be travelled by any feeble current of electricity, a thermo-electric current for instance. Again, this magnetic effect of the steam must be independent of any electricity carried forward by the steam, as when discharged by an Armstrong's jet; for the greatest amount of electricity which 
I have been able to obtain from an Armstong's jet was found sufficient to charge a Leyden jar of about 340 square inches, both sides taken together, twenty-eight times in a minute; the spark being $\frac{1}{3}$ inch long, and the steam at $40 \mathrm{lbs}$. on the inch : now whether the steam passed by the galvanoscope in this highly excited condition, or nearly divested of its electricity, the effect on the galvanoscope was the same, and always many times greater than what could be produced by this largest quantity of frictional electricity that could be obtained (12.). Besides, the frictional electricity of steam increases much as the pressure rises from 10 to 40 lbs. (Armstrong, Matteucci). But I have not generally perceived that the swing of the galvanoscope thus increases with the pressure, but rather the reverse. Also Dr. Faraday has shown, that dry pure steam (11.) cannot develope frictional electricity.

33. From these considerations, I conclude that no continuous electric current passes through or by means of the steam jet; however, many very small currents may circulate in it For instance, if we may suppose that a particle of steam when brought into contact with a particle of colder water developes a momentary current of electricity in a direction bearing some fixed relation to those particles, and then if a continual succession of such particles ensues, the majority of which are similarly placed, we should have something answering to an ordinary electric current, and not very unlike those currents imagined in Ampère's theory of magnetism. This notion accounts for the change in the direction of the magnetism produced by changing the direction of the steam, the effect of the difference of temperature, and the manifest want of equivalency between the steam power expended and the magnetic force obtained. But it may be well to bear in mind, that perhaps magnetism may ultimately come to be regarded as some function of ordinary matter and the æother. I can only look upon the experiments (12.) as going to show that magnetism is not always bound up with current electricity; $I$ should probably have made a decisive experiment on this point, but that the steam apparatus at my disposal was not sufficiently powerful.

34. It is possible instances may be found on board steamers in which the compasses are much disturbed by the steam. Clouds, too, in the act of formation and passing rapidly over a magnet may somewhat affect it.

7 Prospect Place, Ball's Pond Road. 